\title{
STAT3 inhibitor WPI066 as a novel therapeutic agent for renal cell carcinoma
}

\author{
A Horiguchi",', T Asano', K Kuroda', A Sato', J Asakuma', K Ito', M Hayakawa', M Sumitomo' and T Asano' \\ 'Department of Urology, National Defense Medical College, 3-2 Namiki, Tokorozawa-City, Saitama 359-85 I 3, Japan
}

\begin{abstract}
BACKGROUND: Signal transducer and activator of transcription 3 (STAT3) regulates the expression of genes that mediate cell survival, proliferation, and angiogenesis and is aberrantly activated in various types of malignancies, including renal cell carcinoma (RCC). We examined whether it could be a novel therapeutic target for RCC by using the STAT3 inhibitor WPI066.

METHODS: The antitumour activities and related mechanisms of WPI 066 were investigated in vitro on renal cancer cell lines and in vivo on murine xenografts.

RESULTS: In Caki-I and 786-O renal cancer cells, $5 \mu \mathrm{M}$ WPI066 prevented the phosphorylation of STAT3, and $2.5 \mu \mathrm{M}$ WPI066 significantly $(P<0.0 \mathrm{I})$ inhibited cell survival and proliferation. WPI066 suppressed the expression of Bcl-2, induced apoptosis, and inhibited the basal and hypoxia-induced expression of HIFI $\alpha$ and HIF2 $\alpha$, as well as vascular endothelial growth factor secretion into cell culture medium. Human umbilical vascular endothelial cells cocultured with media from WPI066-treated cells showed significantly reduced tubulogenesis $(P<0.05)$. Systemic oral administration of WPI066 to mice for 19 days significantly inhibited the growth of Caki- I xenograft tumours $(P<0.05)$, and pathological analysis of xenografts of WP I066-treated mice showed decreased immunostaining of phosphorylated STAT3 and reduced length of CD34-positive vessels $(P<0.05)$.

CONCLUSIONS: Our results suggest that using WPI066 to inhibit the STAT3 signalling pathway could be a novel therapeutic strategy against RCC.
\end{abstract}

British Journal of Cancer (2010) I 02, I592- 1599. doi:I0.1038/sj.bjc.660569| www.bjcancer.com

Published online II May 2010

(c) 2010 Cancer Research UK

Keywords: STAT3; renal cell carcinoma; angiogenesis; apoptosis

Signal transducer and activator of transcription (STAT) proteins have been shown to have important roles in cytokine and growth factor signalling pathways (Schindler and Darnell, 1995). These proteins are latent in cytoplasm and become activated through tyrosine phosphorylation, which typically occurs through cytokine-receptor-associated kinases, Janus kinases, or growth factor receptor tyrosine kinases (Schindler and Darnell, 1995). The activated STAT proteins then translocate to the nucleus and activate the transcription of target genes (Darnell, 1997). One of the STAT proteins, STAT3, was originally identified as an acute phase response factor activated by the interleukin-6 (IL-6) family of cytokines (Akira et al, 1994). Further studies have shown STAT3 to be activated in response to a variety of other cytokines and growth factors, including epidermal growth factor, platelet-derived growth factor, and transforming growth factor- $\alpha$, as well as by oncogenic proteins such as Src and Ras (Schindler and Darnell, 1995; Darnell, 1997; Aggarwal et al, 2009). STAT3 has also been reported to regulate the transcription of key components of cellcycle control and to modulate the activity of proteins regulating apoptosis (Zushi et al, 1998; Catlett-Falcone et al, 1999; Amin et al, 2004).

*Correspondence: Dr A Horiguchi; E-mail: impreza@cb3.so-net.ne.jp Received I February 2010; revised 8 April 20 I0; accepted I5 April 2010; published online II May 2010
Signal transducer and activator of transcription-3 has been reported to be constitutively activated in various types of malignant tumours, and increased STAT3 activation has been recognised as an indicator of poor prognosis (Huang, 2007; Al Zaid Siddiquee and Turkson, 2008; Aggarwal et al, 2009). Constitutively activated STAT3 signalling in tumours has been shown to promote cell-cycle progression and prevent apoptosis by modulating cell cycleassociated and apoptosis-associated proteins such as cyclin D1 and Bcl-2; this is a possible mechanism of resistance to conventional chemotherapy and radiotherapy (Huang, 2007; Al Zaid Siddiquee and Turkson, 2008; Aggarwal et al, 2009). The activation of STAT3 has also been shown to upregulate vascular endothelial growth factor (VEGF) expression and promote tumour angiogenesis (Niu et al, 2002; Wei et al, 2003). STAT3 has therefore been considered as a potential therapeutic target for cancer treatment.

Renal cell carcinoma (RCC) is the most common malignant tumour of the adult kidney and accounts for approximately $3 \%$ of all adult cancer cases (Bilim et al, 2009; Thompson Coon et al, 2009). Unlike many other malignancies, RCC is generally resistant to conventional therapy (Bilim et al, 2009; Thompson Coon et al, 2009). Having previously reported a high frequency of increased STAT3 activation in RCC, especially in metastatic disease (Horiguchi et al, 2002b), we thought that STAT3 could be a novel therapeutic target for RCC and, in this study, examined whether the STAT3 inhibitor WP1066 shows antitumour activity against $\mathrm{RCC}$ in vitro and in vivo. 


\section{MATERIALS AND METHODS}

\section{Cell culture and reagents}

Human renal cancer cell lines Caki-1 and 786-O (American Tissue Culture Collection, Manassas, VA, USA) were used in this study, and WP1066 (Calbiochem, La Jolla, CA, USA) was dissolved in DMSO at $50 \mathrm{~mm}$. The antibodies used in this study were antibodies against phospho-STAT3 (p-STAT3, Cell Signaling Technology Inc., Beverly, MA, USA), STAT3 (Cell Signaling Technology Inc), phospho-extracellular-activated protein kinase (ERK) (p-ERK, Cell Signaling Technology Inc.), ERK (Cell Signaling Technology Inc.), cleaved poly(ADP-ribose) polymerase (PARP) (Cell Signaling Technology Inc.), Bcl-xl (Cell Signaling Technology Inc.), Bcl-2 (Cell Signaling Technology Inc.), HIF1 $\alpha$ (BD Transduction Laboratories, Lexington, KY, USA), HIF2 $\alpha$ (Novus Biologicals, Littleton, CO, USA), and $\beta$-actin (Chemicon International Inc., Temecula, CA, USA). Horseradish-peroxidase-conjugated secondary antibodies and an enhanced chemiluminescence system were obtained from Amersham Pharm Biotech (Piscataway, NJ, USA).

\section{Cell viability assays and cell counts}

Cell viability was assessed by the MTS assay using the Cell Titer96 AQueous Non-Radioactive Cell Proliferation Assay (Promega, Madison, WI, USA) according to the manufacturer's instructions. Briefly, cells were incubated overnight in 96 -well plates $\left(3 \times 10^{3}\right.$ cells/well) and then treated for $48 \mathrm{~h}$ with the indicated concentration of WP1066 (in DMSO) or with the corresponding amount of DMSO. Two hours after adding MTS, plates were read in a microplate autoreader at a wavelength of $490 \mathrm{~nm}$. The results were expressed as the mean optical density of the six-well set for each group, and the plates were measured twice with similar results. For cell counts, after being incubated overnight in six-well plates $\left(2 \times 10^{4}\right.$ cells/well in triplicate), cells were treated with 2.5 or $5 \mu \mathrm{M}$ WP1066 or with the corresponding amount of DMSO. Total cell numbers in three independent wells in each group were counted at the indicated time by using a hemocytometer, and the mean value of four fields was recorded.

\section{Determination of apoptosis}

Apoptotic cells were assessed by double staining with FITCconjugated annexin- $\mathrm{V}$ and propidium iodide. This staining was carried out using the Annexin V Apoptosis Detection Kit (SantaCruz Biotechnology Inc., Santa Cruz, CA, USA). To observe nuclear morphological changes with a fluorescence microscope, we fixed cells with $4 \%$ paraformaldehyde for $30 \mathrm{~min}$ at room temperature and stained them with $1 \mathrm{~mm}$ Hoechst 33258 (Sigma, St Louis, MO, USA).

\section{Western blot analysis}

Cells that had been treated with 2.5 or $5 \mu \mathrm{M}$ WP1066 or the corresponding amount of DMSO for $24 \mathrm{~h}$ were lysed in RIPA buffer (10 mm Tris- $\mathrm{HCl}, 150 \mathrm{~mm} \mathrm{NaCl}, 1 \%$ Triton X-100, 5 mm EDTA, 1\% sodium deoxycholate, $0.1 \%$ SDS, $1.2 \%$ aprotinin, $5 \mu \mathrm{m}$ leupeptin, $4 \mu \mathrm{M}$ antipain, $1 \mathrm{~mm}$ phenylmethylsulphonyl fluoride, and $0.1 \mathrm{~mm}$ $\mathrm{Na}_{3} \mathrm{VO}_{4}$ ) before equal amounts of proteins were subjected to western blotting as described previously (Horiguchi et al, 2004).

\section{Hypoxia treatment and determination of VEGF production}

Cells were plated at $1 \times 10^{4}$ cells/well in six-well plates in RPMI 1640 containing $10 \%$ FCS, cultured for $24 \mathrm{~h}$ and then washed with serum-free medium and cultured for an additional $24 \mathrm{~h}$ in $1 \mathrm{ml}$ of serum-free medium in the presence or absence of $5 \mu \mathrm{M}$ WP1066 under normoxic or hypoxic $\left(1 \% \mathrm{O}_{2}\right)$ conditions. The medium was collected and centrifuged. The levels of VEGF in the supernatants were analysed using a Quantikine Human VEGF Immunoassay kit (R\&D Systems, Minneapolis, MN, USA) and were normalised to the total protein content measured by the Bradford assay.

\section{Assessment of in vitro angiogenesis}

In vitro angiogenesis was assessed according to the formation of capillary-like structures of human umbilical vascular endothelial cells (HUVECs) cocultured with human diploid fibroblasts as described previously (Horiguchi et al, 2004). The experimental procedure followed the instructions provided with the angiogenesis kit we used (Kurabo, Tokyo, Japan). Briefly, HUVECs were incubated in the conditioned medium, which was replaced at days 4,7 , and 9. On day 11, cells were fixed and stained using an antihuman CD31 antibody (Kurabo) according to the provided instructions. The formation of the capillary network was observed with a microscope at $\times 40$ magnification. The total length of the tube-like structures in five randomly chosen microscope fields was measured by ImageJ (Bethesda, MD, USA) software.

\section{Xenograft model}

Caki-1 cells $\left(3 \times 10^{6}\right.$ cells per $\left.100 \mu \mathrm{l}\right)$ were inoculated subcutaneously into the flanks of nude mice. When the average tumour diameter reached $5 \mathrm{~mm}$, the mice were randomly divided into two groups (eight each), one of which was treated with WP1066 $\left(40 \mathrm{mg} \mathrm{kg}^{-1}\right)$ injected by oral gavage in a mixture of 20 parts DMSO to 80 parts polyethylene glycol 300 (Sigma-Aldrich, Tokyo, Japan) once per day (5 days on and 2 days off) as described elsewhere (Kong et al, 2008), and the other of which was treated with vehicle. The size of each tumour was monitored every 3 or 4 days until the 19th day after the first treatment. Tumour volume $\left(\mathrm{mm}^{3}\right)$ was estimated using the following formula: volume $=$ width $^{2} \times$ length $\times 0.52$. Animal experimentation procedures were reviewed and approved by the National Defense Medical College's Animal Care and Use Committee.

\section{Immunohistochemistry}

Immunohistochemistry was performed as described previously (Horiguchi et al, 2002b). Briefly, formalin-fixed, paraffin-embedded tumour sections $(4 \mu \mathrm{m})$ were deparaffinised in xylene and rehydrated through graded ethanols. The slides were placed in DAKO Target Retrieval Solution High pH (Dako Corporation, Carpinteria, CA, USA) and heated for $40 \mathrm{~min}$ for antigen retrieval. Endogenous peroxidase activity was quenched with Dako Peroxidase Blocking Reagent (Dako Corporation) for $10 \mathrm{~min}$. The sections were incubated in $10 \%$ normal goat serum in PBS for $60 \mathrm{~min}$ at room temperature. After the sections were incubated overnight at $4{ }^{\circ} \mathrm{C}$ with anti-phospho-STAT3 antibody, anti-STAT3 antibody, or anti-CD34 antibody (clone MEC14.7, Hycult Biotechnology, Uden, The Netherlands) at 1:50 dilution in PBS, the slides were stained using a Simple Stain Max PO kit (Nichirei Corporation, Tokyo, Japan) according to the manufacturer's instructions. Reaction products were visualised by immersing slides in $\mathrm{DAB}$ for $5 \mathrm{~min}$. The vascularity in each tumour specimen was estimated using an anti-CD34 antibody. Three areas of most intense vascularisation were selected under a light microscope with a 100-fold magnification. The total length of the tube-like structures was measured by ImageJ software, and for each section, the mean length in the selected areas was recorded.

\section{Statistical analysis}

The statistical significance of differences was evaluated by unpaired $t$-testing, and $P$-values less than 0.05 were considered to indicate significance. 


\section{RESULTS}

\section{WP1066 inactivates STAT3 and suppresses renal cancer cell viability and proliferation}

We first tested whether WP1066 inactivated STAT3 in Caki-1 and 786-O renal cancer cells. STAT3 is latent in the cytoplasm and its activation is accompanied by tyrosine phosphorylation at Tyr705, which induces dimerisation, nuclear translocation, and binding to DNA (Schindler and Darnell, 1995). Cell lysates were subjected to western blotting after Caki-1 and 786-O cells were incubated for $24 \mathrm{~h}$ with 2.5 or $5 \mu \mathrm{M}$ WP1066, concentrations known to suppress STAT3 activity (Ferrajoli et al, 2007; Iwamaru et al, 2007; Kong et al, 2008; Verstovsek et al, 2008). WP1066 inhibited phosphorylation of STAT3 in a dose-dependent manner
(Figure 1A). We also examined its effect on another key component of signal transduction pathways and found that in both cell lines it stimulated the phosphorylation of ERK (Figure 1A).

We next examined the ways in which the viability and proliferation of renal cancer cells were affected when STAT3 activity was inhibited by WP1066. We treated Caki-1 and 786-O cells with the indicated concentration of WP1066 for $48 \mathrm{~h}$ and examined cell viability by MTS assay. The viability of both cell lines was significantly decreased in a dose-dependent manner $(P<0.01)$ (Figure 1B). In triplicate observations made 1 and 2 days after Caki-1 and 786-O cells were treated with $5 \mu \mathrm{M}$ WP1066, it was found that the total number of WP1066-treated cells was significantly $(P<0.01)$ less than the number of DMSO-treated cells (Figure 1C).

A

\begin{tabular}{lcccccc}
\multicolumn{3}{c}{ Caki-1 } & & \multicolumn{3}{c}{$786-\mathrm{O}$} \\
\cline { 6 - 7 } \cline { 5 - 6 } & 2.5 & 5 & & 0 & 2.5 & 5
\end{tabular}

p-STAT3

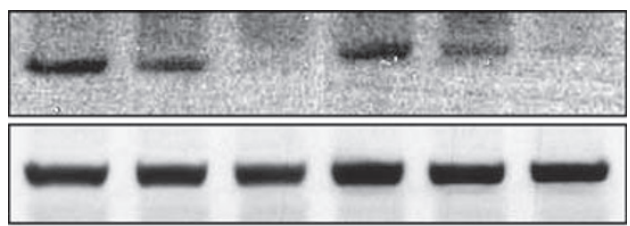

STAT3

p-ERK

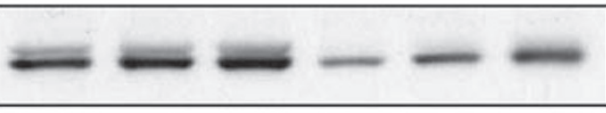

ERK
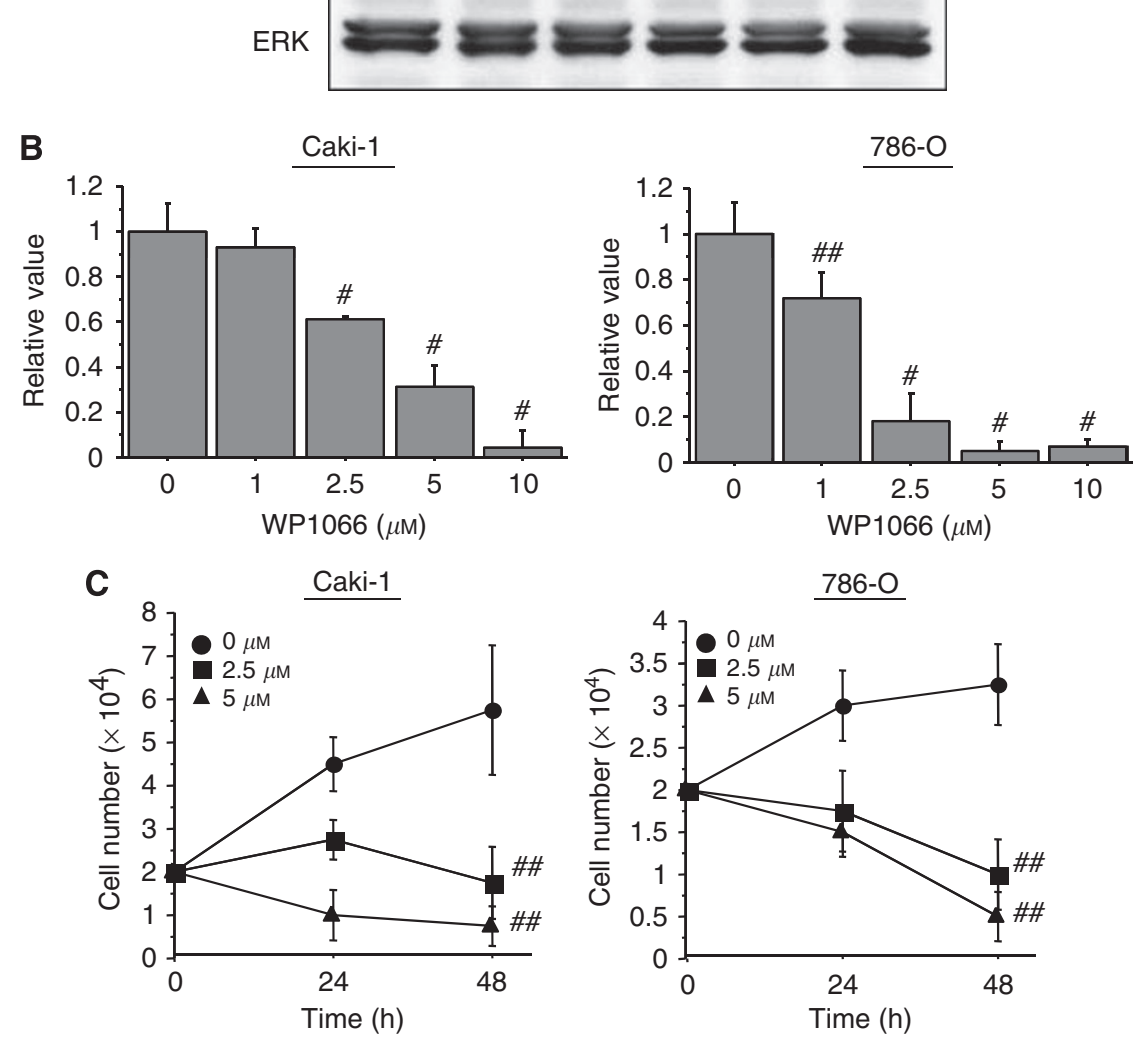

Figure I WPI066 inactivates STAT3 and suppresses the growth and viability of renal cancer cells. (A) WPI066 inhibited STAT3 phosphorylation, while stimulating ERK, in Caki-I and 786-O cells. Caki-I and 786-O cells were treated with the indicated concentration of WPI 066 for $24 \mathrm{~h}$ and cell lysates were subjected to western blotting. (B) MTS-assay-determined viability of Caki-I and 786-O cells treated with the indicated concentration of WPI 066 for $24 \mathrm{~h}$. Note the significantly lower viability of WPI066-treated cells (,$P<0.01$; \#\#, $P<0.05)$. The results are expressed as the mean \pm s.e. of the three sets for each group. (C) Proliferation of Caki-I and 786-O cells in six-well plates treated with the indicated concentration of WPI066. Total cell numbers were counted at 24 and $48 \mathrm{~h}$. Note the significantly reduced proliferation of WPI 066 -treated cells $\left({ }^{\#}, P<0.0 \mathrm{I}\right)$. The results are expressed as the mean \pm s.e. of the three sets for each group. 


\section{WP1066 induces apoptosis in renal cancer cells}

Activated STAT3 has been shown to inhibit apoptosis by upregulating apoptotic regulatory proteins such as antiapoptotic proteins Bcl-2, Bcl-xl, and Mcl-1 (Zushi et al, 1998; Catlett-Falcone et al, 1999; Amin et al, 2004). To examine whether WP1066 would induce apoptosis in renal cancer cells, Caki-1 and 786-O cells incubated for $24 \mathrm{~h}$ with 2.5 or $5 \mu \mathrm{M}$ WP1066 were double stained with annexin- $\mathrm{V}$ and propidium iodide and were analysed by flow cytometry. The percentage of the population that was annexin positive and propidium iodide negative, which are apoptotic cells, was greater in cells treated with WP1066 than in control cells (Figure 2A). The nuclei of WP1066-treated cells seemed lobated and severely fragmented and contained highly condensed chromatin (Figure 2B), which are findings typical of apoptosis. To confirm apoptosis, we examined cells for the presence of PARP cleavage after treatment with WP1066. Cleaved PARP was evident in both Caki-1 and 786-O cells treated with WP1066 for $24 \mathrm{~h}$ (Figure 2C). The expression of Bcl-2 in both cell lines decreased $24 \mathrm{~h}$ after treatment with WP1066, whereas that of Bcl-xl or Mcl-1 did not (Figure 2C).

\section{WP1066 suppresses HIF1 $\alpha$ and HIF2 $\alpha$ expression and VEGF production}

Vascular endothelial growth factor is one of the most potent proangiogenic factors, and renal cancer cell lines, including Caki-1 and 786-O cells, have been shown to produce VEGF (Shinojima et al, 2007). Recent studies have identified that STAT3 is a direct transcription activator of the VEGF gene and that activation of STAT3 leads to tumour angiogenesis (Jung et al, 2005; Xu et al, 2005). We therefore examined whether WP1066 could suppress basal and hypoxia-stimulated production of VEGF. We incubated Caki-1 and 786-O cells with $5 \mu \mathrm{M}$ WP1066 under normoxic or hypoxic $\left(1 \% \mathrm{O}_{2}\right)$ conditions for $24 \mathrm{~h}$ and measured VEGF levels in the supernatants. Caki-1 has the wild-type von-Hippel-Lindau (VHL) gene and expresses both HIF1 $\alpha$ and HIF2 $\alpha$, whereas 786-O has a mutant $V H L$ gene and expresses HIF $2 \alpha$ but not HIF1 $\alpha$ (Shinojima et al, 2007). It has been reported that HIF1 $\alpha$ has a predominant role in VEGF production in Caki-1 cells but that HIF $2 \alpha$ regulates VEGF production in 786-O cells (Shinojima et al, 2007). We found the VEGF level in Caki-1 cells incubated under hypoxic conditions to be significantly $(60 \%)$ higher than that in Caki-1 cells incubated under normoxic conditions $(P<0.05$, Figure $3 \mathrm{~A}$ ). The VEGF level in 786-O cells, on the other hand, was not increased under hypoxic conditions (Figure 3A). WP1066 significantly $(P<0.01)$ suppressed basal and hypoxia-stimulated VEGF production in both Caki-1 and 786-O cells (Figure 3A). A recent study has demonstrated that STAT3 increased the levels of HIF $1 \alpha$ in Caki- 1 cells by blocking its degradation and accelerating its de novo synthesis (Jung et al, 2005). We further examined whether WP1066 modulates HIF1 $\alpha$ or HIF2 $\alpha$ expression. In Caki-1 cells, hypoxic incubation increased the expression of HIF $1 \alpha$, HIF $2 \alpha$, and phosphorylated STAT3, and these increases were suppressed by WP1066 (Figure 3B). In 786-O cells, on the other hand, levels of HIF $2 \alpha$ and phosphorylated STAT3 expression were
A
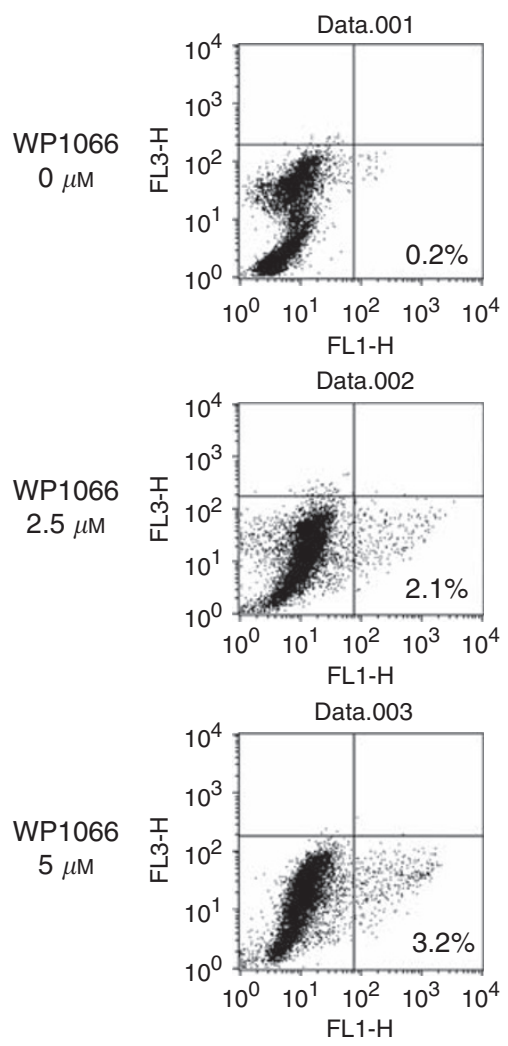
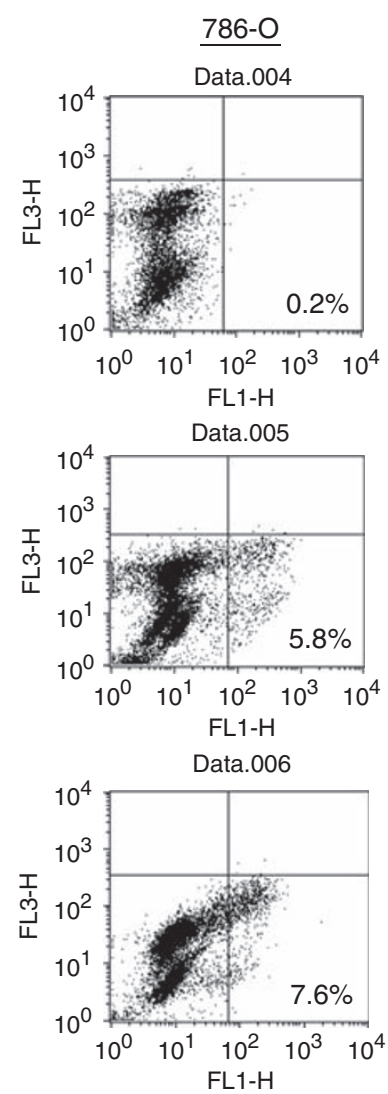

B

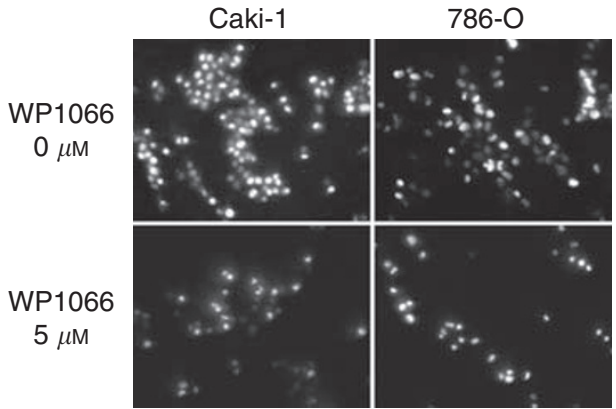

C

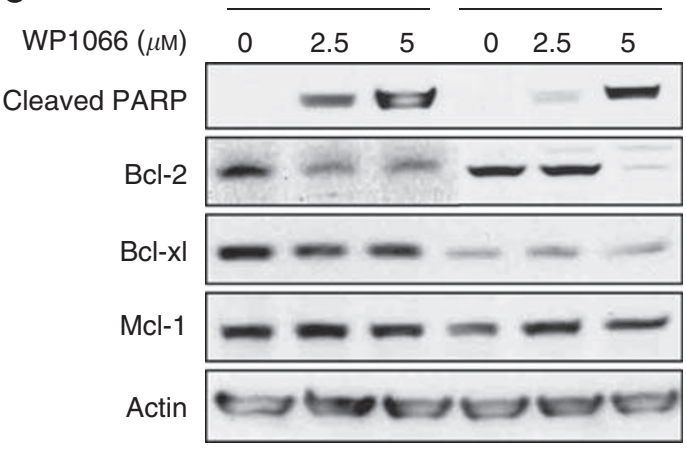

Figure 2 WPI066 downregulates antiapoptotic protein Bcl-2 and induces apoptosis in renal cancer cells. (A) Annexin $\mathrm{V}$ staining for apoptosis assay in Caki-I and 786-O cells incubated for $24 \mathrm{~h}$ with the indicated concentration of WPI066. The percentages of annexin-V-positive- and propidium-iodidenegative (early apoptosis) fractions are indicated. (B) Nuclear morphologies observed by fluorescence microscopy after staining with Hoechst 33258 after Caki-I and 786-O cells had been incubated for $24 \mathrm{~h}$ with the indicated concentration of WP I066. Note the fragmented and condensed nuclei characteristic of apoptosis. (C) Western blot analysis of apoptosis-related proteins. Cells were treated with the indicated concentration of WP 066 for $24 \mathrm{~h}$ and subjected to western blotting. Actin was used as an internal control. 


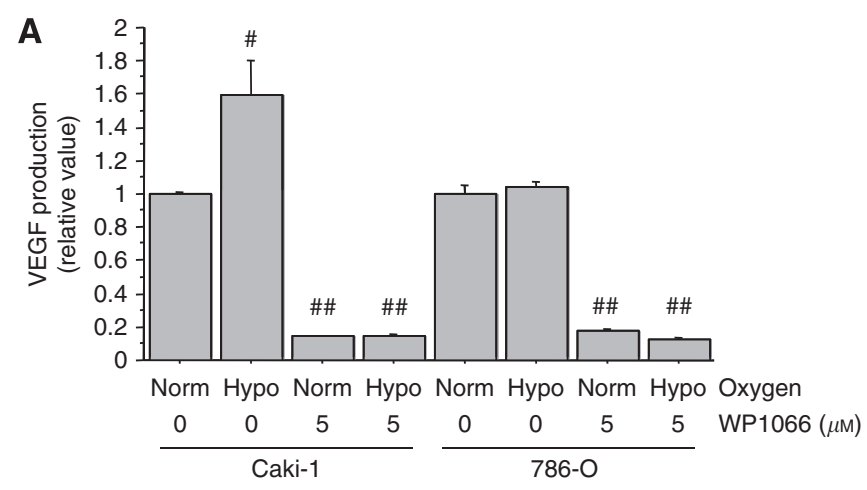

B

\begin{tabular}{rccccccccc}
\cline { 3 - 7 } Oxygen & Norm & Hypo & Norm & Hypo & Norm & Hypo & Norm & Hypo \\
WP1066 $(\mu \mathrm{M})$ & 0 & 0 & 5 & 5 & 0 & 0 & 5 & 5
\end{tabular}

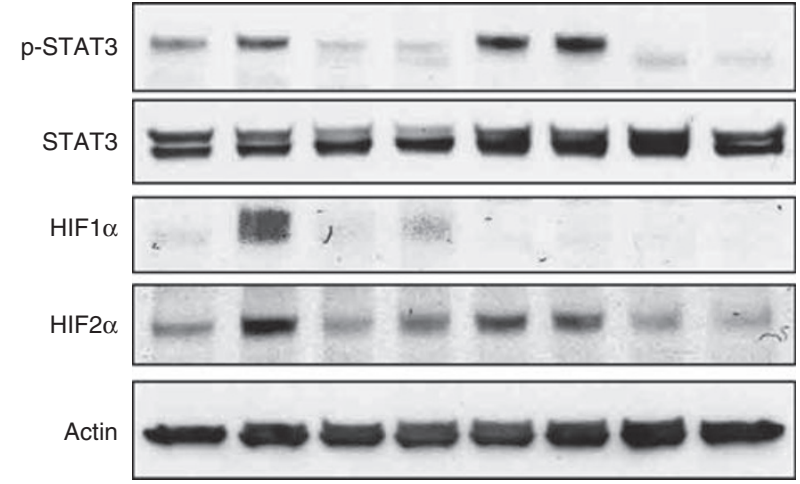

Figure 3 WPI066 downregulates HIFI $\alpha$ and HIF2 $\alpha$ expression and reduces VEGF production in renal cancer cells. (A) Caki-I and 786-O cells were incubated with the indicated concentration of WPI066 under normoxic (norm) or hypoxic (hypo, $1 \% \mathrm{O}_{2}$ ) conditions for $24 \mathrm{~h}$, and the VEGF levels in the cell culture media were measured by ELISA. Hypoxic conditions stimulated VEGF production in Caki- I cells but not in 786-O cells (\#, $P<0.05)$. VEGF production under both normoxic and hypoxic conditions was significantly suppressed by treatment with WPI066 $(\# \#, P<0.01)$. The results are expressed as the mean \pm s.e. of the three sets for each group. (B) Caki-I and 786-O cells were incubated with the indicated concentration of WPI066 under normoxic or hypoxic $\left(1 \% \mathrm{O}_{2}\right)$ conditions for $6 \mathrm{~h}$, and cell lysates were subjected to western blotting. Hypoxic conditions stimulated STAT3 phosphorylation and upregulated $H I F I \alpha$ and HIF2 $\alpha$ expression in Caki-I cells, and these effects were suppressed by treatment with WPI066. Hypoxic conditions had no effect on STAT3 phosphorylation or HIF2 $\alpha$ expression in 786-O cells, both of which were suppressed by treatment with WPI066.

not changed by hypoxic incubation but were suppressed by WP1066 (Figure 3B).

\section{WP1066 inhibits in vitro angiogenesis}

We next examined the effect of WP1066 on in vitro angiogenesis by using an HUVEC tubulogenesis assay. We incubated Caki-1 and 786-O cells with or without $5 \mu \mathrm{M}$ WP1066 under normoxic or hypoxic conditions for $24 \mathrm{~h}$ and collected the supernatants. These conditioned media were applied to HUVEC plates cultured in matrigel and the length of the tubular structures was measured. The tubular structures in HUVECs cultured in conditioned media obtained when Caki-1 cells had been incubated under hypoxic conditions were significantly $(P<0.05)$ longer than those in HUVECs cultured in conditioned media obtained when Caki-1 cells had been incubated under normoxic conditions (Figures 4A and B). On the other hand, hypoxic incubation had no effect on the length of tubular structures in HUVECs cultured in conditioned media obtained from 786-O cells (Figures 4A and B). The length of tubular structures in HUVEC cultured in conditioned media obtained from both Caki-1 and 786-O cells treated with WP1066 was significantly $(P<0.01)$ shorter than that in HUVECs cultured in conditioned media obtained from cells not treated with WP1066 (Figures 4A and B).

\section{WP1066 inhibits tumour growth in the murine xenograft model of Caki-1 cells}

As WP1066 inhibited the growth of renal cancer cells and angiogenesis in vitro, we tested the efficacy of WP1066 against renal cancer xenografts. WP1066 administrated orally is more efficacious and less toxic than WP1066 injected intraperitonealy or intravenously (Kong et al, 2008). When established Caki-1 xenografts were treated, 5 days on and 2 days off for a total of 19 days, with WP1066 (40 $\mathrm{mg} \mathrm{kg}^{-1}$ orally) or only the vehicle (DMSO and polyethylene glycol 300), the mean volume of tumours treated with WP1066 $\left(304.7 \pm 50.0 \mathrm{~mm}^{3}\right)$ was significantly $(P<0.05)$ smaller than that of tumours treated with only the vehicle $\left(788.9 \pm 239.7 \mathrm{~mm}^{3}\right.$, Figures $5 \mathrm{~A}$ and $\left.\mathrm{B}\right)$.

\section{WP1066 inactivates STAT3 in vivo and inhibits tumour angiogenesis}

We next performed immunohistochemical analysis of Caki-1 xenograft tumours to examine whether WP1066 inhibited its growth by inactivating STAT3. STAT3 is latent in the cytoplasm and its activation is accompanied by tyrosine phosphorylation, which induces dimerisation, nuclear translocation, and binding to DNA (Schindler and Darnell, 1995). Consistent with the current understanding of STAT3 signalling pathways, predominant nuclear immunostaining of phosphorylated STAT3 was observed in the vehicle-treated control tumours (Figure 5C, upper left). In WP1066-treated tumours, on the other hand, there was little p-STAT3 immunostaining (Figure 5C, upper right). Similar total STAT3 immunostaining was observed in both vehicle-treated and WP1066-treated tumours, suggesting that WP1066 inhibited phosphorylation of STAT3 without modulating STAT3 expression (Figure 5C, middle row). To examine whether WP1066 inhibits tumour angiogenesis, we immunostained xenograft tumours with CD34 and measured the length of CD34-positive vessels in each tumour (Figure 5C, lower row). The mean total length of CD34positive vessels in WP1066-treated tumours was significantly $(P<0.05)$ shorter than that in vehicle-treated control tumours (Figure 5D).

\section{DISCUSSION}

In this study, we showed that in Caki-1 and 786-O renal cancer cells, STAT3 inhibitor WP1066 inactivated the STAT3 signalling pathway and induced apoptosis, accompanied by reduced Bcl-2 expression. WP1066 downregulated HIF $1 \alpha$ and HIF $2 \alpha$ expression under both normoxic and hypoxic conditions, resulting in reduced VEGF production and in vitro angiogenesis. Moreover, oral administration of WP1066 significantly suppressed tumour angiogenesis and inhibited the growth of xenograft tumours generated from Caki-1 cells. Our results suggest that inhibiting the STAT3 signalling pathway by using WP1066 could be a novel therapeutic strategy against RCC.

Activated STAT3 fosters tumourigenesis by preventing apoptosis, enhancing proliferation, angiogenesis, invasiveness, and immune evasion (Huang, 2007; Al Zaid Siddiquee and Turkson, 2008; Aggarwal et al, 2009). In various types of malignant tumours, including leukaemia and cancers of the breast, head and neck, melanoma, prostate, pancreas, and colon, activation of STAT3 is 
A
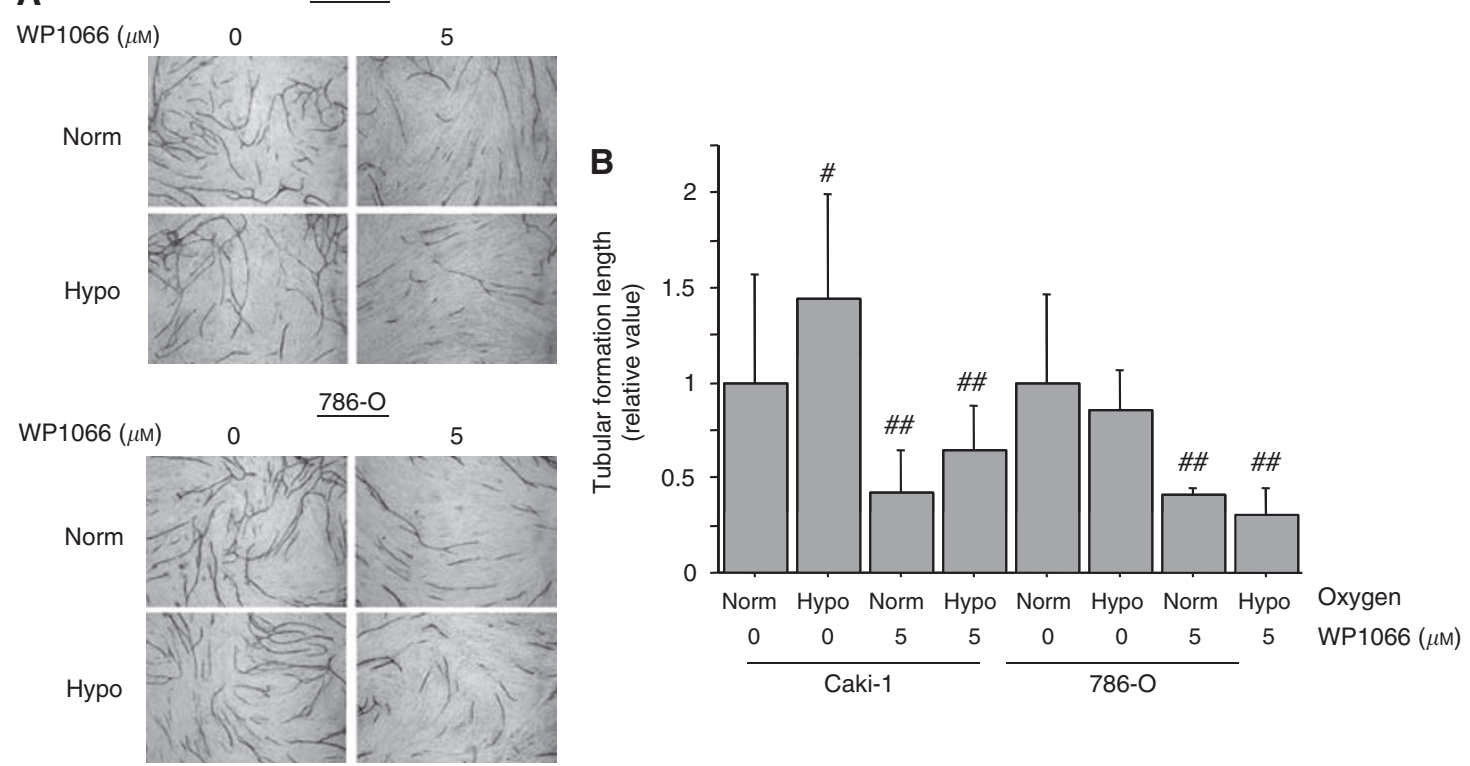

Figure 4 WPI066 inhibited in vitro angiogenesis. The HUVECs were incubated in a cell-conditioned medium with $5 \mu$ M WPI 066 under normoxic (norm) or hypoxic (hypo, I\% $\mathrm{O}_{2}$ ) conditions. After incubation for I I days, HUVECs were fixed and stained with an anti-human CD3I antibody. (A) Representative photomicrographs $(\times 40)$ of HUVEC tubular formations. (B) Tubular formation length was quantified in five randomly selected fields. $\left(^{\#}, P<0.05\right.$; $\# \#, P<0.01$ vs cells cultured without WPI 066 under normoxic conditions). The results are expressed as the mean \pm s.e. of the three sets for each group.

aberrantly increased (Huang, 2007; Al Zaid Siddiquee and Turkson, 2008; Aggarwal et al, 2009). We have previously identified a high frequency (50\%) of increased STAT3 activation in RCC by immunohistochemical analysis (Horiguchi et al, 2002b). The STAT3 is also known to be involved in regulating cancer metastasis, and activation of STAT3 correlates with lymph node and distant metastasis (Huang, 2007). High levels of STAT3 activation are also significantly associated with the presence of metastasis and poor survival rate in RCC (Horiguchi et al, 2002b). These studies showed that inhibitors of the STAT3 signalling pathway have enormous potential in the treatment of cancer and drove us to examine its efficacy against RCC.

Several strategies for developing effective inhibitors of STAT3 have been pursued. One small-molecule STAT3 inhibitor, AG490, was originally selected from a group of tyrphostins screened for their ability to block Jak2 activity and has been shown to inhibit growth and induce apoptosis in some types of cancer cells, including renal cancer cells (Meydan et al, 1996; Horiguchi et al, 2002a). However, AG490 can inhibit STAT3 only at high concentrations (IC50 value $=50-100 \mu \mathrm{M}$ ) and therefore has not been shown to have an in vivo antitumour effect in animal models (Meydan et al, 1996; Horiguchi et al, 2002a). Priebe and his colleagues synthesised WP1066 by modifying the structure of AG490, and WP1066 has been shown to inhibit STAT3 activity and to have a potent antitumour effect on malignant glioma cells, both in vitro and in vivo (Iwamaru et al, 2007). Marked antitumour activity of WP1066 has also been shown against head and neck carcinoma, pancreatic cancer, bladder cancer, B-cell non-Hodgkin's lymphoma, and chronic myelogenous leukaemia (Ferrajoli et al, 2007; Kong et al, 2008; Verstovsek et al, 2008). We previously showed that the proliferation of Caki-1 cells is inhibited by high concentrations of AG490 ( IC $_{50}$ value $=30.0 \mu \mathrm{M}$ ) (Horiguchi et al, 2002a), and here we showed that the proliferation of Caki-1 cells is significantly inhibited by WP1066 at a concentration as low as $2.5 \mu \mathrm{M}$. Moreover, oral administration of WP1066 significantly inhibited the growth of Caki-1 xenografts, and pathological examination showed reduced STAT3 activation in WP1066-treated xenografts. Thus, in accordance with previous studies (Ferrajoli et al, 2007; Hussain et al, 2007; Iwamaru et al, 2007; Kong et al,
2008; Verstovsek et al, 2008), WP1066 is a potent STAT3 inhibitor both in vitro and in vivo.

In addition to the inhibitory effect on STAT3 activation, WP1066 has also been shown to inhibit Jak2/STAT3 activation induced by cytokines and STAT5 (Ferrajoli et al, 2007; Iwamaru et al, 2007; Kong et al, 2008). In our preliminary experiments, we examined the activation of Jak2 and STAT5 in Caki-1 and 786-O cells cultured in media with $10 \%$ FBS and did not detect activated Jak2 or activated STAT5 in either cell line (data not shown). Moreover, treatment with WP1066 had no effect on their activation status. On the other hand, treatment of Caki-1 and 786-O cells with WP1066 simultaneously decreased STAT3 activation and increased ERK activation. The constitutive activation of ERK has been shown to occur frequently in RCC, especially in clear cell carcinoma, and the levels of activated ERK increased with increasing tumour size and tumour stage (Oka et al, 1995; Campbell et al, 2009). Moreover, increased activation of ERK is an independent indicator of poor prognosis in patients with RCC (Campbell et al, 2009). In our preliminary study, we further examined activated ERK expression immunohistochemically in xenograft tumours from mice treated with WP1066 and mice treated with vehicle. The staining intensity in tumours treated with WP1066 was much stronger than that in control tumours, which was the inverse of what was observed with p-STAT3 immunostaining (data not shown). Because ERK activation has been shown to be essential for mitogenic signals and to promote cancer proliferation and metastasis in various types of cancer including RCC (Campbell et al, 2009), WP1066-induced activation of ERK might compromise its antitumour activity.

Activated STAT3 has been shown to protect tumour cells from apoptosis by regulating genes encoding antiapoptosis-associated proteins, such as Bcl-2, Bcl-xl, and Mcl-1 (Zushi et al, 1998; CatlettFalcone et al, 1999; Amin et al, 2004). Bcl-2 is frequently expressed in RCC, and a Bcl-2 overexpression may explain the resistance of RCC to conventional chemotherapy and radiotherapy (Tomita et al, 1996; Huang et al, 1999). We previously showed that AG490 inhibited STAT3 and induced apoptosis accompanied by the downregulation of Bcl-2 in renal cancer ACHN cells (Horiguchi et al, 2002a). In line with our previous study, we herein showed 
A

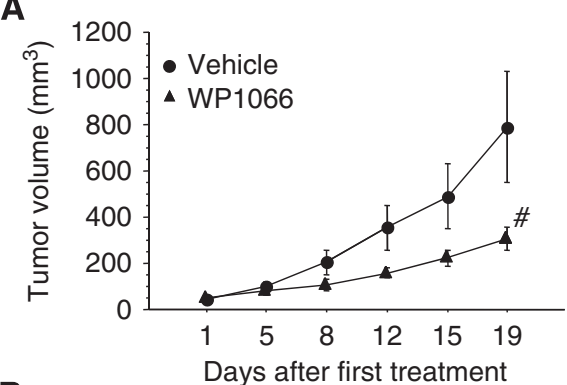

B

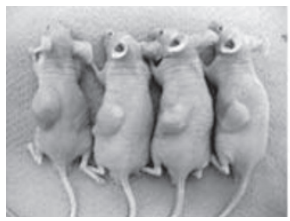

Vehicle-treated

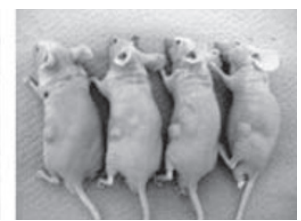

WP1066-treated
C

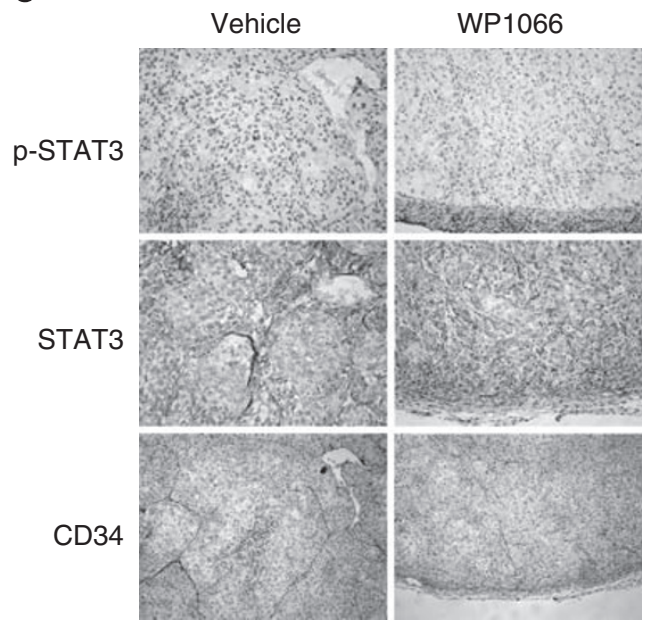

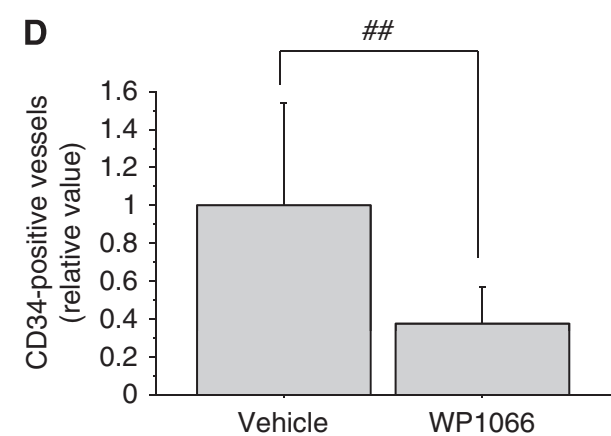

Figure 5 WPI066 inhibits tumour growth in the murine xenograft model of Caki-I cells. (A) Established Caki-I tumour xenografts in athymic male nude mice were treated with WPI066 (40 $\left.\mathrm{mg} \mathrm{kg}^{-1}, n=8\right)$ or vehicle (20\% DMSO-80\% polyethylene glycol $\left.300, n=8\right)$ by oral gavage once per day for 5 days (followed by a rest for 2 days) for a total of 19 days. Tumour volume in WP I 066-treated mice on day 19 after the first administration was significantly smaller than that in control vehicle-treated mice $(\#, P<0.05)$. (B) Representative photographs of WPI066-treated mice and vehicle-treated control mice. (C) Immunohistochemical analysis of representative samples of xenograft tumours. Formalin-fixed xenograft tumours were immunostained with anti-pSTAT3, STAT3, or CD34 antibodies. Note decreased level of nuclear p-STAT3 immunostaining (upper right) and decreased tubular length of CD34positive vessels (lower right) in WPI066-treated tumours compared with vehicle-treated control tumours. (D) Length of CD34-positive vessels was quantified in selected fields. ( $\left.{ }^{\#}, P<0.05\right)$.

that WP1066 downregulated Bcl-2 expression effectively and induced apoptosis in both Caki-1 and 786-O cells.

Recent studies have identified STAT3 as a direct transcription activator of the VEGF gene and showed that activation of STAT3 leads to tumour angiogenesis in vivo (Niu et al, 2002; Wei et al, 2003). Mutations of VHL tumour suppressor protein are found in most clear-cell RCC, and loss of VHL protein function leads to elevated levels of HIF $\alpha$ and consequent overexpression of VEGF (Motzer et al, 2006). Recent studies demonstrated that STAT3 has a pivotal role in the regulation of HIF1 $\alpha$ protein expression and stability and enhances HIF $1 \alpha$-mediated expression of VEGF by interacting with HIF1 $\alpha$ (Jung et al, 2005; Xu et al, 2005). Here, we showed that incubating Caki-1 cells under hypoxic conditions activated STAT3, upregulated HIF1 $\alpha$ expression, and enhanced VEGF production, and that all of these effects were inhibited by treatment with $5 \mu \mathrm{M}$ WP1066. Jung et al previously showed that AG490 inhibited hypoxia-induced activation of STAT3, as well as HIF1 $\alpha$ expression and VEGF production, but this inhibition required a much higher concentration $(30 \mu \mathrm{M})$ (Jung et al, 2005). On the other hand, VEGF production is not stimulated by hypoxia in VHL-mutated 786-O cells (Shinojima et al, 2007). Accordingly, we found hypoxic conditions to have no effect on VEGF production or on STAT3 phosphorylation levels in 786-O cells, both of which were inhibited by treatment with WP1066. Interestingly, WP1066 markedly inhibited the expression of HIF $2 \alpha$, which has a crucial role in VEGF transcriptional regulation in
786-O cells (Shinojima et al, 2007). Our results suggest that not only HIF $1 \alpha$ but also HIF $2 \alpha$ might be regulated by STAT3. The HUVECs that were cocultured with the supernatants from Caki-1 and 786-O cells incubated with WP1066 showed reduced tubular formation, and our pathological assessment of the xenograft tumours showed that WP1066 reduced STAT3 activation and the length of CD34-positive microvessels. Our data suggest that WP1066 suppresses VEGF production and tumour angiogenesis under both normoxic and hypoxic conditions regardless of the VHL gene mutation status. To our knowledge, this report is the first to show that WP1066 inhibits tumour angiogenesis.

Surgical resection remains the mainstay of therapy for localised RCC, and metastatic RCC is highly refractory to conventional radiation therapy and chemotherapy (Bilim et al, 2009; Thompson Coon et al, 2009). The recent discovery and clinical development of some targeted agents have expanded treatment options in metastatic RCC (Escudier et al, 2009; Motzer et al, 2009), but complete response is rare and most patients eventually fail the treatment with targeted agents. The management of advanced RCC therefore remains a significant challenge to clinicians. Our study suggests that WP1066 is potentially useful for treating metastatic RCC.

\section{Conflict of interest}

The authors declare no conflict of interest. 


\section{REFERENCES}

Aggarwal BB, Kunnumakkara AB, Harikumar KB, Gupta SR, Tharakan ST, Koca C, Dey S, Sung B (2009) Signal transducer and activator of transcription-3, inflammation, and cancer: how intimate is the relationship? Ann N Y Acad Sci 1171: 59-76

Akira S, Nishio Y, Inoue M, Wang XJ, Wei S, Matsusaka T, Yoshida K, Sudo T, Naruto M, Kishimoto T (1994) Molecular cloning of APRF, a novel IFN-stimulated gene factor 3 p91-related transcription factor involved in the gp130-mediated signaling pathway. Cell 77: 63-71

Al Zaid Siddiquee K, Turkson J (2008) STAT3 as a target for inducing apoptosis in solid and hematological tumors. Cell Res 18: 254-267

Amin HM, McDonnell TJ, Ma Y, Lin Q, Fujio Y, Kunisada K, Leventaki V, Das P, Rassidakis GZ, Cutler C, Medeiros LJ, Lai R (2004) Selective inhibition of STAT3 induces apoptosis and G(1) cell cycle arrest in ALKpositive anaplastic large cell lymphoma. Oncogene 23: 5426-5434

Bilim V, Ougolkov A, Yuuki K, Naito S, Kawazoe H, Muto A, Oya M, Billadeau D, Motoyama T, Tomita Y (2009) Glycogen synthase kinase-3: a new therapeutic target in renal cell carcinoma. Br J Cancer 101: $2005-2014$

Campbell L, Nuttall R, Griffiths D, Gumbleton M (2009) Activated extracellular signal-regulated kinase is an independent prognostic factor in clinically confined renal cell carcinoma. Cancer 115: $3457-3467$

Catlett-Falcone R, Landowski TH, Oshiro MM, Turkson J, Levitzki A, Savino R, Ciliberto G, Moscinski L, Fernandez-Luna JL, Nunez G, Dalton WS, Jove R (1999) Constitutive activation of Stat 3 signaling confers resistance to apoptosis in human U266 myeloma cells. Immunity 10: $105-115$

Darnell Jr JE (1997) STATs and gene regulation. Science 277: 1630-1635

Escudier B, Szczylik C, Hutson TE, Demkow T, Staehler M, Rolland F, Negrier S, Laferriere N, Scheuring UJ, Cella D, Shah S, Bukowski RM (2009) Randomized phase II trial of first-line treatment with sorafenib versus interferon Alfa-2a in patients with metastatic renal cell carcinoma. J Clin Oncol 27: 1280-1289

Ferrajoli A, Faderl S, Van Q, Koch P, Harris D, Liu Z, Hazan-Halevy I, Wang Y, Kantarjian HM, Priebe W, Estrov Z (2007) WP1066 disrupts Janus kinase-2 and induces caspase-dependent apoptosis in acute myelogenous leukemia cells. Cancer Res 67: 11291-11299

Horiguchi A, Oya M, Marumo K, Murai M (2002a) STAT3, but not ERKs, mediates the IL-6-induced proliferation of renal cancer cells, ACHN and 769P. Kidney Int 61: $926-938$

Horiguchi A, Oya M, Shimada T, Uchida A, Marumo K, Murai M (2002b) Activation of signal transducer and activator of transcription 3 in renal cell carcinoma: a study of incidence and its association with pathological features and clinical outcome. J Urol 168: $762-765$

Horiguchi A, Sumitomo M, Asakuma J, Asano T, Hayakawa M (2004) 3-hydroxy-3-methylglutaryl-coenzyme a reductase inhibitor, fluvastatin, as a novel agent for prophylaxis of renal cancer metastasis. Clin Cancer Res 10: $8648-8655$

Huang A, Fone PD, Gandour-Edwards R, White RW, Low RK (1999) Immunohistochemical analysis of BCL-2 protein expression in renal cell carcinoma. J Urol 162: 610-613

Huang S (2007) Regulation of metastases by signal transducer and activator of transcription 3 signaling pathway: clinical implications. Clin Cancer Res 13: $1362-1366$

Hussain SF, Kong LY, Jordan J, Conrad C, Madden T, Fokt I, Priebe W, Heimberger AB (2007) A novel small molecule inhibitor of signal transducers and activators of transcription 3 reverses immune tolerance in malignant glioma patients. Cancer Res 67: 9630-9636

Iwamaru A, Szymanski S, Iwado E, Aoki H, Yokoyama T, Fokt I, Hess K, Conrad C, Madden T, Sawaya R, Kondo S, Priebe W, Kondo Y (2007) A novel inhibitor of the STAT3 pathway induces apoptosis in malignant glioma cells both in vitro and in vivo. Oncogene 26: $2435-2444$
Jung JE, Lee HG, Cho IH, Chung DH, Yoon SH, Yang YM, Lee JW, Choi S, Park JW, Ye SK, Chung MH (2005) STAT3 is a potential modulator of HIF-1-mediated VEGF expression in human renal carcinoma cells. FASEB J 19: $1296-1298$

Kong LY, Abou-Ghazal MK, Wei J, Chakraborty A, Sun W, Qiao W, Fuller GN, Fokt I, Grimm EA, Schmittling RJ, Archer Jr GE, Sampson JH, Priebe W, Heimberger AB (2008) A novel inhibitor of signal transducers and activators of transcription 3 activation is efficacious against established central nervous system melanoma and inhibits regulatory $\mathrm{T}$ cells. Clin Cancer Res 14: 5759-5768

Meydan N, Grunberger T, Dadi H, Shahar M, Arpaia E, Lapidot Z, Leeder JS, Freedman M, Cohen A, Gazit A, Levitzki A, Roifman CM (1996) Inhibition of acute lymphoblastic leukaemia by a Jak-2 inhibitor. Nature 379: $645-648$

Motzer RJ, Hutson TE, Tomczak P, Michaelson MD, Bukowski RM, Oudard S, Negrier S, Szczylik C, Pili R, Bjarnason GA, Garcia-del-Muro X, Sosman JA, Solska E, Wilding G, Thompson JA, Kim ST, Chen I, Huang X, Figlin RA (2009) Overall survival and updated results for sunitinib compared with interferon alfa in patients with metastatic renal cell carcinoma. J Clin Oncol 27: $3584-3590$

Motzer RJ, Rini BI, Bukowski RM, Curti BD, George DJ, Hudes GR, Redman BG, Margolin KA, Merchan JR, Wilding G, Ginsberg MS, Bacik J, Kim ST, Baum CM, Michaelson MD (2006) Sunitinib in patients with metastatic renal cell carcinoma. JAMA 295: 2516-2524

Niu G, Wright KL, Huang M, Song L, Haura E, Turkson J, Zhang S, Wang T, Sinibaldi D, Coppola D, Heller R, Ellis LM, Karras J, Bromberg J, Pardoll D, Jove R, Yu H (2002) Constitutive Stat3 activity up-regulates VEGF expression and tumor angiogenesis. Oncogene 21: 2000-2008

Oka H, Chatani Y, Hoshino R, Ogawa O, Kakehi Y, Terachi T, Okada Y, Kawaichi M, Kohno M, Yoshida O (1995) Constitutive activation of mitogen-activated protein (MAP) kinases in human renal cell carcinoma. Cancer Res 55: $4182-4187$

Schindler C, Darnell Jr JE (1995) Transcriptional responses to polypeptide ligands: the JAK-STAT pathway. Annu Rev Biochem 64: 621-651

Shinojima T, Oya M, Takayanagi A, Mizuno R, Shimizu N, Murai M (2007) Renal cancer cells lacking hypoxia inducible factor (HIF)-1alpha expression maintain vascular endothelial growth factor expression through HIF-2alpha. Carcinogenesis 28: 529-536

Thompson Coon JS, Liu Z, Hoyle M, Rogers G, Green C, Moxham T, Welch K, Stein K (2009) Sunitinib and bevacizumab for first-line treatment of metastatic renal cell carcinoma: a systematic review and indirect comparison of clinical effectiveness. Br J Cancer 101: 238-243

Tomita Y, Bilim V, Kawasaki T, Takahashi K, Okan I, Magnusson KP, Wiman KG (1996) Frequent expression of Bcl-2 in renal-cell carcinomas carrying wild-type p53. Int J Cancer 66: $322-325$

Verstovsek S, Manshouri T, Quintas-Cardama A, Harris D, Cortes J, Giles FJ, Kantarjian H, Priebe W, Estrov Z (2008) WP1066, a novel JAK2 inhibitor, suppresses proliferation and induces apoptosis in erythroid human cells carrying the JAK2 V617F mutation. Clin Cancer Res 14: $788-796$

Wei D, Le X, Zheng L, Wang L, Frey JA, Gao AC, Peng Z, Huang S, Xiong HQ, Abbruzzese JL, Xie K (2003) Stat3 activation regulates the expression of vascular endothelial growth factor and human pancreatic cancer angiogenesis and metastasis. Oncogene 22: 319-329

Xu Q, Briggs J, Park S, Niu G, Kortylewski M, Zhang S, Gritsko T, Turkson J, Kay H, Semenza GL, Cheng JQ, Jove R, Yu H (2005) Targeting Stat3 blocks both HIF-1 and VEGF expression induced by multiple oncogenic growth signaling pathways. Oncogene 24: 5552-5560

Zushi S, Shinomura Y, Kiyohara T, Miyazaki Y, Kondo S, Sugimachi M, Higashimoto Y, Kanayama S, Matsuzawa Y (1998) STAT3 mediates the survival signal in oncogenic ras-transfected intestinal epithelial cells. Int J Cancer 78: $326-330$ 